\title{
LA CONSTRUCCIÓN DE LA INSTERSUBJETIVIDAD \\ DESDE LA HERMENÉUTICA TRASCENDENTAL
}

The building from the intersubjetive

transcendental hermeneutics

\author{
Antonio Luis TeRRONes RodRíGUez \\ Universitat de Valencia/ Valencia-España \\ antonioluis.terrones(a)gmail.com
}

\begin{abstract}
Resumen
En este artículo se busca reflexionar sobre cómo el diálogo es una poderosa herramienta para utilizar en aquellos programas educativos que deseen contribuir con la transformación de la sociedad. Es por ello, que se hace necesario vincular la hermenéutica a la praxis de las ciencias sociales. La hermenéutica puede brindar a las ciencias sociales una metodología de encuentro de perspectivas a través de la intersubjetividad. La intersubjetividad, establecida a través del diálogo, puede posibilitar espacios de acercamiento a la hora de construir un conocimiento colectivo en el ámbito educativo. La ética, también como disciplina filosófica, puede servir para fundamentar la praxis educativa orientada hacia la construcción de ciudadanía en las sociedades democráticas. La ética también es importante precisamente porque fomenta la responsabilidad, esa virtud tan necesaria en todas las sociedades, y más si cabe en las actuales que se enfrentan a desafíos nunca antes vistos. La hermenéutica y la ética pueden servir para fundamentar nuevos programas educativos, tanto es así, que el filósofo alemán Apel, con sus contribuciones filosóficas a partir de la ética discursiva, esclarece el tema de las comunidades, que suponen ni más ni menos que espacios de diálogo y construcción de conocimiento colectivo. Así pues, una hermosa contribución que podría hacer el pensamiento de Apel, a partir de sus postulados éticos y hermenéuticos, a la educación es la de generación de espacios de encuentros que propicien el diálogo, tan necesario hoy en día, sobre todo en los jóvenes.
\end{abstract}

Educación, ética discursiva, hermenéutica, diálogo, comunidad.

Forma sugerida de citar: Terrones Rodríguez, Antonio Luis (2017). La construcción de la instersubjetividad desde la Hermenéutica trascendental. Sophia, colección de Filosofía de la Educación, 22(1), pp. 175-192.

* Doctorando de la Universitat de Valencia. Máster en Ética y Democracia. Licenciado en Filosofía. 


\begin{abstract}
This article seeks to reflect on how the dialogue is a powerful tool to use in those educational programs that wish to contribute to the transformation of society. That is why, it is necessary to link hermeneutics to praxis of social sciences. Hermeneutics can provide social science methodology meeting prospects through intersubjectivity. Intersubjectivity, established through dialogue, can enable spaces approach when building a collective knowledge in education. Ethics, as well as philosophical discipline, can serve to inform educational practice-oriented construction of citizenship in democratic societies. Ethics is also important precisely because it fosters responsibility, that virtue so necessary in all societies, and more so in the current that enfretan to unprecedented challenges. Hermeneutics and Ethics can serve to support new educational programs, so much so, that the German philosopher Apel, with his philosophical from the discursive Ethics contributions, clarifies the issue of communities, which account for no less than spaces dialogue and collective construction of knowledge. Thus, a beautiful contribution it could make the thought of Apel, from its ethical principles and hermeneutical, education is the generation of meeting spaces that enable dialogue, so necessary today, especially in young.
\end{abstract}

Keywords

Education, discourse ethics, hermeneutics, dialogue, community.

\title{
Introducción
}

En este artículo se verá cómo la hermenéutica y su influencia sobre las ciencias humanas posibilitará el desarrollo de la ética discursiva para generar el diálogo que se hace tan necesario para la educación en la actualidad y para la construcción de una democracia participativa. Por lo tanto, se tratará de tejer redes de intersubjetividad entre las personas a fin de participar en la elaboración de lo colectivo, ya sea en lo educativo o en lo político.

Como se puede observar, en la praxis de las ciencias humanas, el ser humano se convierte a la vez en sujeto y objeto de la investigación y eso es algo que servirá para dirigir la mirada. La hermenéutica, con su aporte intersubjetivo en la investigación, allanará el camino hacia acuerdos sobre los fines y los valores que se abordarán en las clases como comunidades de investigación. La fundamentación hermenéutica, y más concretamente la ética discursiva, se hace necesaria, porque se optará por una base filosófica sólida para desarrollar luego la propuesta de una educación cívica y en valores que haya elegido el camino de la comunidad de investigación que ofrece el programa de Filosofía para Niños. Por tanto, la Filosofía se convierte en una importante herramienta para fundamentar una educación democrática basada en el diálogo intersubjetivo, pues de lo que se trata es de elaborar la educación desde una perspectiva ética, en este caso desde la ética discursiva.

Es importante que los programas educativos sirvan para construir sociedades democráticas con bases sólidas sobre el diálogo. Las socieda- 
des del mundo se enfrentan a conflictos que pueden gestionarse de diferentes formas, dependiendo del caso, pero que todos pueden apoyarse en la herramienta del diálogo, De ahí, surge la necesidad de que la Filosofía contribuya a la construcción de sociedades democráticas por medio de la educación, a partir de la hermenéutica y la ética.

Un programa educativo que en la actualidad está dando mucho de qué hablar y que cada vez está siendo objeto de más seminarios y congresos, es el programa de Filosofía para Niños, impulsado por Matthew Lipman y que siguen enriqueciendo muchos docentes en la actualidad, sobre todo desde el ámbito de la Filosofía, aunque también desde otros ámbitos.

La metodología utilizada en esta investigación es la bibliográfica, pues los textos utilizados han aportado un enriquecedor espíritu para la reflexión llevada a cabo a lo largo del diálogo.

Primeramente se lleva a cabo una vinculación entre la hermenéutica y las ciencias sociales, estableciendo conexiones en lo relativo a los métodos. De esa conexión se podrá observar cómo la Teoría Crítica jugará un papel fundamental. La ética discursiva también será abordada en lo relativo al ámbito educativo, pues la reflexión que nos brinda este campo ético ayudará para generar los espacios que propicien el diálogo. La normatividad y la responsabilidad también deben ser dos puntos básicos para la educación y las sociedades democráticas. Dichos puntos serán tratados como básicos en la formación del êthos ciudadano.

\section{El aporte de la hermenéutica crítica de las ciencias sociales}

Existe una gran oportunidad al elaborar la unidad investigación-enseñanza que surge del aporte de la hermenéutica. Unidad que es el caballo de batalla contra los dogmatismos, pues situará, en virtud de los contenidos y conocimientos, los acuerdos pedagógicos que surgirán de la relación comunicativa entre el investigador de las ciencias sociales y el educando. A diferencia de las ciencias naturales que se sirven únicamente de una comunidad de expertos para contrastar y hacer válidas sus investigaciones, los investigadores propios de la hermenéutica ofrecen su trabajo a una comunidad amplia que se convierte en su consejera y compañera de trabajo.

Es aquí donde posiblemente pueda hacérsele evidente al científico puro que un acuerdo intersubjetivo metódicamente disciplinado no puede ser substituido por métodos objetivistas de explicación de la conducta o de simulación o manipulación técnica de la misma (Apel, 1985, p.138). 
Los investigadores que orientan su mirada desde la hermenéutica se sirven del acompañamiento de una comunidad amplia, lo que da muestra de su compromiso social y político. Este apunte señala que al tenerse en cuenta diversos criterios de valoración, la actividad investigadora se desarrollará en virtud de una acción crítica. Pudiendo llegar a decir que la hermenéutica dota de criticismo a la investigación de las ciencias sociales. El enfoque hermenéutico dirigido sobre las actividades educativas y políticas aporta una apertura de sentido al mundo. Esta apertura de sentido se da cuando el intérprete sitúa él mismo su existencia en el horizonte de conocimientos y de conceptos que trata de comprender, algo que luego se tendrá en cuenta a la hora de proponer la forma "freiriana" del diálogo. En cambio las ciencias empírico-analíticas simplemente se limitan a basar sus intenciones investigadoras en situar los aspectos del mundo como objetivados sin posicionar al sujeto intérprete dentro de ese mundo. No existe pues aquí un entendimiento en el que el sujeto intérprete se haya también situado en la experiencia sino que se encuentra fuera de ella.

El fenómeno de la comunicación y la interacción intersubjetivas, inmediatamente aceptado por las ciencias hermenéuticas como base y objetivo de sus operaciones cognoscitivas, este fenómeno social originario, es el que tratan de excluir en la medida de lo posible las ciencias sociales estilizadas de modo empírico-analítico (nomológico) es decir, de superarlo a favor de la relación de sujeto y objeto del conocimiento, presupuesta en las ciencias naturales (Apel, 1985, p. 131).

Los investigadores de las ciencias empírico-analíticas reducen su actividad a decir cómo son las cosas, lo que da muestra de una excesiva objetivación. Mientras que los investigadores hermenéutas de las ciencias empírico-hermenéuticas centran su empeño en comprender aquello que se les presenta. De esta manera el camino de la hermenéutica ofrece una manera racional de construir una relación recíproca entre la subjetividad y la intersubjetividad. A partir de lo que se ha ido dilucidando en lo relacionado a la aportación de la hermenéutica sobre las ciencias sociales, se pueden poner de manifiesto dos aspectos: por un lado la propuesta hermenéutica considera que los intérpretes no pueden tener, ya que ni es posible ni es viable, una perspectiva con intenciones objetivadoras, puesto que como se ha comentado anteriormente, el sujeto intérprete se sitúa en el interior de las observaciones. Y, por otro lado, el sujeto intérprete adopta una actitud realizadora lo que conlleva una radical dependencia del contexto pues al encontrarse inmerso en él se encuentra irremediablemente influenciado. El método intersubjetivo que propone Karl-Otto Apel ayuda a eliminar un subjetivismo exacerbado porque incorpora la 
interacción de muchas subjetividades y el diálogo entre ellos. Es el resultado de la negociación y el diálogo entre diversidad de sujetos.

En la mirada empírico-hermenéutica de las ciencias sociales no existe la posibilidad de abstracción del sujeto cognoscente (como si se da en el enfoque empírico-analítico) pues existe una relación recíproca sujeto-contexto-sujeto. La interacción entre el (los) sujeto(s) investigador(es) y el contexto, posibilitará una construcción teórica comunitaria y participativa. Lo que da muestra de la flexibilidad de la discusión, y además servirá para estar en la base del diálogo que es necesario establecer como método de trabajo e investigación propio del programa de Filosofía para Niños (Lipman, 2001).

Estas diferencias de enfoque le sirvieron a la Escuela de Fráncfort para llevar a cabo un duro ataque contra el positivismo y sus diversas formas de expresión, que dirigió la crítica al objetivismo de las ciencias. Dicha crítica se centró en las contraproducentes implicaciones ideológicas que tendría sobre la sociedad la aplicación del modelo de las ciencias naturales en las ciencias sociales. Es decir el estudio de los procesos y acontecimientos sociales desde un punto de vista que tuviera en cuenta la supuesta unidad objetivista a la hora de llevar a cabo la aplicación del método. Así mismo, la Teoría Crítica emanada de la Escuela de Fráncfort, puso en tela de juicio esta pretensión objetivadora sobre las ciencias sociales advirtiendo de las consecuencias reduccionistas y por tanto desafortunadas de dicho enfoque.

Esta teoría, como Adela Cortina muestra:

Busca el apoyo de las ciencias empíricas, pero, en tanto que disciplina hermenéutica, se esfuerza inevitablemente por comprender el sentido de los acontecimientos; en tanto que saber crítico, intenta desentrañar las desfiguraciones que hacen de la sociedad una sociedad ideologizada, con vistas a lograr su emancipación (Cortina, 2008, p. 49).

La Teoría Crítica destaca que el modulo causal de compresión de la realidad tenía unas implicaciones ideológicas que ya señaló en el año 1986 Apel expresando que la "continuación lineal de la utopía científicotecnológica del dominio del hombre sobre la naturaleza, a través de la utopía tecnocrática del dominio del hombre sobre la naturaleza humana como cuasi-naturaleza" (Apel, 1986, p. 186), muestra un claro interés por diseñar y reproducir las condiciones sociales, económicas y políticas para llevar a cabo un férreo control del comportamiento humano. La excesiva positivización de las ciencias y de cualquier forma de conocimiento posible puede conducir a consecuencias nada deseables y por tanto nocivas y 
destructivas para la sociedad, cuando la actividad humana se gestiona de una manera tecnocrática.

Se hace pues necesario plantear una contundente alternativa. La historia social sería reconstruida críticamente a partir de la consideración racional de la ética que planteaba una comunicación libre de dominación, en el marco de una comunidad ideal de comunicación. La Teoría Crítica influenciada por la tradición hermenéutica y el pragmatismo de la filosofía analítica comenzó a plantearse la posibilidad de una nueva fundamentación, una fundamentación que tuviera un carácter normativo en lo concerniente al diálogo y por lo tanto teórico-comunicativa. Se trataría de un nuevo planteamiento para las ciencias sociales que dirigiera ahora su atención hacia la organización democrática de la praxis de la sociedad. En este contexto y ante la necesidad de una alternativa, Habermas y Apel 180 desarrollaron una ética que tuviera un trasfondo teórico pero con los pies en la tierra, es decir, orientada a la praxis social.

Una vez planteada la nueva alternativa ética que surgió de la necesidad de una normatividad más adecuada para el ámbito de las ciencias sociales, se hace también necesario mostrar qué implicaciones conlleva esta nueva normatividad ética. En un primer momento ofrece la posibilidad de hacer una reconstrucción hermenéutica y crítica de las condiciones históricas conducentes al estado actual de las ciencias sociales y su praxis, introduciendo en el discurso las experiencias de los sujetos que forman parte de la argumentación. La normatividad ética planteada por Apel, pero también por Habermas, se aplica a la experiencia cotidiana, por lo que está dotada de un carácter pragmático. El télos que se encuentra aquí presente no es ya solo la búsqueda de consensos, algo que podría no ser imprescindible para el programa de Filosofía para Niños, pero que constituiría la regulación de las situaciones cotidianas analizadas o enfocadas, en este caso en las clases.

Las argumentaciones se establecen como el pilar fundamental que apuntalan la legitimación de toda norma situacional. Este sostenimiento se postula como la condición necesaria para que se produzca un acuerdo sobre los criterios que orientarán la práctica de una posible propuesta o alternativa futura. Por tanto, la implementación de la norma requiere el reconocimiento del sujeto argumentante que participa del diálogo discursivo. La propuesta de Apel tiene una doble dimensión, por un lado, una dimensión trascendental porque se estructura a partir de un marco normativo que no se reduce a ninguna situación concreta y, por otro lado, una dimensión pragmática porque tienen en cuenta las condiciones lingüísticas presentes en la realidad cotidiana concreta. 
El lenguaje tiene una doble dimensión, esto es, hermenéutico-trascendental. Es la estructura sobre la que se levanta el marco trascendental de constitución del sentido pero también permite posicionarse en una situación excéntrica y por tanto crítica respecto de todo sentido. De aquí se sigue que cuando se aprende un lenguaje, se está también aprendiendo el uso comunicativo de ese lenguaje y por lo tanto lo que es poner en práctica una determinada regla. Así pues, se puede concluir de esto, que todo lenguaje encuentra su origen en una comunidad ideal de comunicación.

Se considera importante la aportación e influencia que Peirce tuvo sobre Apel y Habermas en relación a la ética discursiva, pues su propuesta de una transformación del método de acuerdo científico fue observada muy de cerca por ambos. Apel lo deja muy claro cuando sostiene lo siguiente:

A mi juicio, la concepción desarrollada por Ch. S. Peirce acerca de la formación del consenso en la "comunidad científica" puede ofrecer una primera idea de cómo cabe pensar todavía filosóficamente una transformación de la "filosofía de los grandes pensadores". Según Peirce, esta comunidad de experimentación y de interpretación reemplazaría a la época del apriorismos solipsista basado en la evidencia y establecería de forma metódicamente controlable -como concreción del sujeto transcendental kantiano- aquel consenso veritativo que, en la época que precedió -según Peirce- al -método a priori de los grandes pensadores individuales, se obtuvo coactivamente utilizando el método de la autoridad (Apel, 1985, p.12).

Peirce está mostrando ya como va a plantear una transformación semiótica de la filosofía kantiana. Hasta Kant, la filosofía de la conciencia se caracterizaba por una reducida relación entre el sujeto y el objeto, en donde el objeto se convertía en lo que era representable y la conciencia en aquello que llevaba a cabo la representación del objeto representable. Pues bien, el giro transformador que plantea Peirce, consiste en concebir a la conciencia misma como un objeto de reflexión y de crítica. La gran aportación de Peirce para la ética discursiva, es precisamente poner en tela de juicio el paradigma de conciencia. Este cuestionamiento del paradigma tiene una gran relevancia dentro de la filosofía práctica. Habermas resume muy bien esto que se está tratando acerca de la aportación de Peirce:

Tras el giro pragmático, la verdad de un signo proposicional necesita demostrarse por la referencia de ese signo al objeto y ello a la vez mediante razones que pueden ser aceptados por una comunidad de interpretación. En el nuevo paradigma, pues, el papel del sujeto no lo asume Per se el lenguaje, sino la comunicación mediada por argumentos de 
quienes se ponen a hablar entre sí para entenderse sobre algo en el mundo. El sitio de la subjetividad pasa a ocuparlo una praxis intersubjetiva de entendimiento que genera de por sí secuencias infinitas de signos e interpretaciones (Habermas, 1996, p. 44).

Lo que Peirce quiso transmitir con su propuesta de transformación semiótica debe ser entendido dentro de lo que él llama una comunidad de investigadores que desarrollan su actividad bajo unas condiciones ideales. Esto le servirá a la ética discursiva para desarrollar su idea de una comunidad ideal de comunicación y más adelante para poder sentar las bases del diálogo que se establecerá en el ámbito de la educación, pues lo que plantea Peirce se fundamenta en una intersubjetividad, sobre cuya base se propondrá en el siguiente capítulo el diálogo.

La idea de una comunidad de comunicación ilimitada e ideal de la que habla Apel, encuentra su origen en una voluntad previa que tiene que ver con una condición contrafáctica. Todos los sujetos particulares presentes en cualquier comunidad particular tienen sus propios intereses particulares. No obstante una posible manera de superar esta reducción a intereses particulares desde diferentes perspectivas, puede ser la de anticipar y por tanto mostrarse con predeterminación y voluntad a aceptar que haya otros agentes con origen en diversas comunidades reales. Esta anticipación a una comunidad más amplia, "no particular", permitirá romper con el rígido contexto comunitario que en muchas ocasiones determinan y fundamentan las comunidades reales. A colación de este aspecto Apel sostiene lo siguiente:

En este postulado, de la comunidad no particular, se basa, por así decirlo, la dimensión de una transformación trascendental -semiótica o trascendental-pragmática- de la filosofía trascendental kantiana, de su concepto de razón teórica y práctica. Se podría hablar de un comunitarismo trascendental o de una filosofía trascendental de la intersubjetividad, en el sentido de una reciprocidad estrictamente generalizada (Apel, 1995, pp. 22-23).

La comunidad ideal de comunicación se presenta como un espacio de participación que supera los límites circunstanciales y particulares de cada comunidad real de comunicación. Por tanto, ambas comunidades de comunicación, la real y la ideal toman partida como espacios opuestos pero que en realidad no son contradictorios sino vinculados y dependientes para poder dotar de sentido y poder establecer el diálogo. Dentro del planteamiento de Apel se puede observar una deseada racionalidad comunicativa que se construye bajo la anticipación con carácter contra- 
fáctico, de la que anteriormente se ha hablado. Dicha proyección anticipativa es decisiva para poder establecer el diálogo y construir intersubjetividad en una comunidad ideal de comunicación. En las siguientes líneas Apel lo expresa muy bien:

Porque a través de ella se presenta un télos normativamente fundamentado para el proceso de reconstruir, y este télos no se identifica con la realidad de las condiciones sociales actuales sino con las circunstancias a que cada comunidad argumentante aspira [...] De este modo, se establece un ideal éticamente relevante para todo miembro de la "comunidad de investigadores"; pues la idea del carácter fundamentalmente social del conocimiento posible de lo real, fuerza a la solidaridad ética entre los investigadores particulares y la comunidad, pues sólo en ella puede alcanzarse el fin de la investigación (Apel, 1997, pp. 149-150).

Es importante también comenzar ya a tratar lo que se considera como la construcción de la intersubjetividad y por tanto del sentimiento de identificación con el plural 'nosotros'.

La voluntad relacionada con la anticipación contrafáctica de la que se ha hablado en párrafos anteriores, la construye el sentimiento de reciprocidad a través de la racionalidad comunicativa. No obstante la condición para que esta construcción de reciprocidad se dé, tiene que establecerse un diálogo intersubjetivo entre los diversos sujetos argumentantes, es decir, entre el colectivo. Acontece pues, una traslación desde el 'yo' al 'nosotros'. La construcción del êthos común aparece desde la perspectiva de reconocimiento del colectivo del que siempre se ha formado parte, del cual, en determinadas ocasiones, debido a un individualismo de intereses exacerbados, ha habido un distanciamiento. A partir del momento en el que se configura el êthos común, las orientaciones y no son fijadas desde la singularidad, sino que son sometidas a un diálogo intersubjetivo que las discute y las valida cuantas veces sea necesario.

Existe una relación entre la identidad subjetiva y la intersubjetividad. Esto se entiende mejor si se observa que para tener conciencia de sí mismo hay que tenerla como referencia de algo y ese algo son los demás, es decir la intersubjetividad. El acto de construcción de identidad es un acto hermenéutico ya que se funda en una reflexión que implica comprenderse a sí mismo y comprender a los demás. No se puede concebir a la individualidad como aislada puesto que se encuentra inmersa en un contexto que lo conforman también las intersubjetividades. Lo que se pretende mostrar es que lo individual se encuentra ligado inexorablemente a lo colectivo. Una praxis ética, propia de los postulados de la Éti- 
ca discursiva, puede ser una eficaz herramienta en el ámbito educativo, como se verá más adelante.

\section{La Ética discursiva en el ámbito de la educación}

Uno de los objetivos fundamentales de las ciencias humanas reside en alcanzar una práctica comunicativa que haga posible la "unidad entre investigación y enseñanza, en orden a la formación de una opinión pública" (Apel, 1985, p. 121).

Se puede entender la pedagogía como una disciplina perteneciente al campo de la educación y que se encarga de mediar en la relación que tienen la teoría y la praxis. Una relación que puede ser concebida de diferentes modos, pero que aquí se ceñirá a los dos aspectos que Apel consideraba más relevantes.

La pedagogía entendida como ciencia social empírico-nomológica pertenece al ámbito del positivismo. De esta manera la pedagogía queda reducida a mera tecnología porque es entendida como un simple método práctico de aplicación. Como se ha visto en el párrafo anterior, la pedagogía se encarga de mediar la relación teoría-praxis, pero aquí la relación es principalmente tecnológica. La acción del pedagogo sobre el educando persigue únicamente fines académicos-cognitivos. Esta pedagogía está estrechamente ligada con la racionalidad instrumental de la que habla la Teoría Crítica, o si no se puede leer lo que dice Theodor W. Adorno:

Semejante concepción no es de todo utópica, y menos aún si imaginamos la función de esta pedagogía en el contexto social de un sistema tecnocráticamente perfeccionado de total manipulación de la gran masa por una pequeña élite de manipuladores (Adorno, 1998, pp. 133-134).

Esta no es precisamente la pedagogía sobre la que se quiere hacer hincapié, porque no se fundamenta en una racionalidad discursiva sino en una racionalidad instrumental. Es una pedagogía que no se construye a partir del diálogo intersubjetivo de los afectados, en este caso de los educadores y de los educandos. La capacidad de diálogo propositivo de los educadores, para establecer una pedagogía más participativa, queda mutilada. En la actualidad en España se puede observar un ejemplo claro relacionado con esto que se está tratando. Dicho ejemplo, es la LOMCE, que ha sido ampliamente rechazada por la comunidad educativa en su gran mayoría, ya que no se ha sometido a un proceso de elaboración participativo de los sectores afectados. 
La pedagogía entendida como ciencia crítico-social implica un compromiso a la hora de considerar a esta disciplina a partir de una mirada crítica. Esta mirada crítica está encaminada a la reflexión permanente sobre la actividad pedagógica, haciendo hincapié en los objetivos a cumplir planteados y en los métodos que se aplicarán para lograr dichos objetivos, pero siempre desde un punto de vista emancipatorio. Emancipatorio, porque rompe con el mecanismo de dominación que plantea la pedagogía entendida como ciencia social empírico-nomológica dentro del marco de la racionalidad instrumental en la que se desarrolla el modelo capitalista.

La Teoría Crítica significa un toque de atención para la práctica pedagógica que se encuentra dentro de la lógica de la racionalidad instrumental y que, por lo tanto, no establece, a partir de la reflexión crítica, unos objetivos educativos que estén cercanos a los problemas concretos de la sociedad. Hay por lo tanto un distanciamiento entre las investigaciones que se dan dentro de los muros de las escuelas y las universidades y lo que realmente ocurre en la calle, fuera de esos muros. Respecto a este distanciamiento espacio-investigativo Adorno comenta lo siguiente:

A menudo los maestros son percibidos bajo las mismas categorías que el protagonista desgraciado de una tragicomedia de estilo naturista; cabría hablar, con la mirada puesta en él, de un complejo de ensoñación. Están bajo la permanente sospecha de vivir fuera del mundo. (...) En el cliché de esa vida fuera del mundo se entremezclan los rasgos infantiles de algunos maestros con los de muchos alumnos (Adorno, 1998, p. 73).

La Educación entendida desde la hermenéutica puede romper el interés de manipulación de la racionalidad instrumental en aras de una pedagogía crítica que se construya en virtud a una responsabilidad moral y política. Y que además tenga intención de llevar a cabo una continua reflexión crítica para mejorar la formación orientada a la acción y la participación social. Se hace más necesario que nunca, en un mundo manipulado por la racionalidad instrumental, formar ciudadanía en virtud a una mentalidad crítica y autónoma pero que se fundamente en un diálogo intersubjetivo.

Esta nueva manera de plantear la pedagogía puede ser la "piedra en el zapato" de aquellos que según Apel se guían por:

Una mentalidad de adaptación oportunista y enemiga de la reflexión, que dispone a los estudiantes a dejarse formar en una universidad gobernada por las necesidades económicas de capitalismo tardío y reformada según los principios de racionalidad de la teoría de la producción como "especialistas idiotas" utilizables a voluntad (Apel, 1985, p. 124). 
Esta manera crítica de mediar la relación entre teoría y praxis es la que precisamente plantea una pedagogía basada en la ética discursiva.

Entre las intenciones que se persiguen con una educación discursiva se puede encontrar un êthos de responsabilidad social y de compromiso político. Aquella educación que carece de actitud crítica, es una educación que reproduce el sistema sin posibilidad de cambios, legitimando el statu quo, el establishment caracterizado por el dominio de una clase sobre otra, por la tecnocracia y por lo tanto por la razón instrumental. Que no reconoce la capacidad de reflexión entre la teoría y la praxis planteada por una educación emancipadora, y que tampoco potencia la capacidad de juicio por lo que supone un caldo de cultivo para el adoctrinamiento de las masas. Otra de las fatales consecuencias que tiene este tipo de educación acrítica es el fomento del escepticismo ético, pues no parte de una ética mínima (Cortina, 2010), 186 lo que puede desembocar en la aparición de actitudes perversas y extremas como el racismo, la xenofobia, etc. Esta sería una situación violenta basada en el dogmatismo, la radicalización y en un individualismo que no reconocería a los otros como otros sino como cosas, apareciendo así también, como no podía ser de otra manera, el fenómeno de la cosificación.

Por ello, frente a la razón instrumental es planteada una pedagogía alternativa, de construcción colectiva, donde se hace necesaria la influencia de la ética discursiva. El enfoque discursivo plantea una alternativa en el tratamiento de los conflictos y las situaciones, basándose en criterios racionales y razonables. Desde la mirada influyente de la teoría sobre la praxis y desde la proyección de dicha praxis.

Lo que se plantea aquí también es la concepción misma de conocimiento, entendiendo que éste es una construcción social en la que están involucradas diversas subjetividades, reivindicando por ello, frente a la "monocultura" del conocimiento científico, una ecología de saberes, reivindicando el diálogo entre diferentes formas de pensar, conocer, valorar y sentir; frente a la verticalidad de instituciones y sistema académico se promueven relaciones horizontales entre los diferentes categorías de sujetos involucrados en la producción de conocimiento. De esta forma, si la teoría ha de orientar a la acción, la teoría misma debe ser una construcción legitimada a través del diálogo y de la argumentación, potenciando las diversas subjetividades que hacen posible la construcción de conocimiento y la transformación de prácticas y realidades sociales hacia la emancipación. De esta manera los sujetos ya no tomarán partido en actitudes escépticas como anteriormente se ha señalado, sino que serán responsables en sus acciones, pues estarán bien forjadas en el aprendizaje y en la argumentación del diálogo. 
De lo que se trata es de promover una moral cívica que encuentre sus reglas enraizadas en la vida pública, donde los valores y criterios hayan surgido como un producto de las relaciones democráticas y donde la responsabilidad social y el compromiso político tengan un peso importante. La educación moral tiene que tener por tanto una base teórica y procedimental que encuentre su origen en la ética discursiva para poder proporcionar un corpus teórico a la altura de nuestro tiempo. Las pretensiones de diálogo y participación que propone la ética discursiva según Emilio Martínez Navarro estarían:

En la base de los valores de ética cívica que ya comparten los ciudadanos de las sociedades abiertas, pluralistas y democráticas en las que queremos vivir los ciudadanos de la época moderna, y que por ello suelen estar recogidos como valores constitucionales en la mayor parte de los países políticamente avanzados: libertad, igualdad, solidaridad, respeto activo y actitud de resolución dialogada de conflictos. Con este trasfondo ético general, la enseñanza y las demás actividades legítimas podrían ser reinterpretadas, reformuladas de un modo crítico (Martínez, 2010, p. 90).

La educación moral debe ser el ámbito en el que se propicie una expresión y un intercambio de juicios, razones y sentimientos a partir de los cuales se construya una regulación de intereses y acciones de la ciudadanía. No obstante es fundamental que la educación moral promueva el ejercicio de la actitud crítica y del juicio responsable. En este sentido, la ética discursiva tiene que jugar un papel fundamental como guía de orientación para el proceso de educación moral. Es imposible renunciar a las orientaciones teóricas si de verdad se quiere incidir en la vida pública democrática. Por tanto es de suma importancia no renunciar a las orientaciones teóricas para la educación de la moral como bien dice Walter Benjamin:

Quizá nos tiente la idea de cortar de raíz cualquier disquisición teórica acerca de la asignatura 'Moral', con la afirmación de que las influencias sobre la moral son un asunto puramente personal, que se sustrae a toda esquematización y normalización. Estemos o no en lo cierto, hay un hecho concreto que para nada tiene en cuenta ese principio: la enseñanza de la moral es fomentada, porque se la considera necesaria. Y si se fomenta teóricamente la enseñanza de la moral, también es preciso analizar teóricamente esta exigencia (Benjamin, 1974, p. 9).

No obstante también hay que dejar claro que no se trata de cerrarse en un marco teórico concreto porque si no se le estaría haciendo el juego al dogmatismo. Se trata más bien de contar con un corpus teórico que se encuentre relacionado dialécticamente con la realidad concreta en la que 
se esté desarrollando, para así promover la reflexión y el desarrollo de una conciencia crítica y responsable. En la búsqueda de una educación moral para la construcción de un êthos común y democrático, se hace necesario renunciar a las teorías científicas herméticas y cerradas. La educación democrática no solo está en la práctica sino en la construcción misma de la teoría, que es también acción, pero debe ser también una acción política, educativa y democrática, ya que además la teoría siempre se construye a partir de la experiencia, Hay que incluir metodologías participativas y por tanto a muchos sujetos. En el conocimiento académico actual, vertical, la teoría solo ha incorporado el conocimiento que las élites y el sistema político de dominación quiere, y a ese conocimiento le llaman científico y el que no les interesa lo excluyen y lo combaten. Así pues, según Apel:

No se trata de una distinción ontológica-estática entre política y filosofía, entre teoría y praxis. No debemos ignorar que, desde que en la configuración de las ciencias particulares se adoptó una "teoría" parcelada por abstracciones constitutivas de objetos, una de las tareas esenciales de la filosofía ha de consistir en fundamentar críticamente desde los intereses cognoscitivos del hombres las abstracciones que realiza la teoría en las ciencias particulares; y esto implica superarlas a través de una mediación entre teoría y praxis (Apel, 1985, p. 11).

\section{La normatividad y la responsabilidad moral en la comunidad moral educativa}

La norma puede considerarse como un elemento vertebrador a la hora de construir comunidades morales. La norma propicia la noción de comunidad a través de una educación de los valores morales que pasan con el tiempo a considerarse como derecho y obligaciones a partir de los cuales se configura la noción de justicia. Sin embargo para la configuración de una moralidad que posibilite la aparición de un sentimiento de comunidad es necesario que exista una voluntad ética. Walter Benjamin trata esta cuestión, pues como él señala "la meta de la educación moral es la formación de la voluntad ética; y, sin embargo, no hay nada más inaccesible que esa voluntad ética puesto que, como tal, no constituye una dimensión psicológica tratable con determinados medios" (Benjamin, 1974, p.11).

Lo legal tiene que ajustarse a la norma, pues será a través de ella a partir de la que se construya el concepto de comunidad. "La esencia de la constitución ética de comunidades parecería estar representada por una íntima fusión entre rigor ético en la conciencia de la obligación común y 
confirmación de la ética en el orden de la comunidad" (Benjamin, 1974, p. 12). Como sabemos una norma adquiere el estatus de reconocimiento y legitimidad cuando una comunidad se siente reflejada en dicha norma y puede por tanto respetarla y velar por su cumplimiento. Este hecho representa el constante proceso de reconocimiento y validación que tiene que estar presente en toda norma. Por tanto legitimidad y reconocimiento de la norma son necesarios para seguir construyendo y reconstruyendo modos de regulación. La reconstrucción de una norma implica el sometimiento de ésta a la crítica social para mejorarla en miras a una mayor legitimidad.

Es importante no confundirse pensando que la educación moral adquiere un carácter excesivamente deontológico, puesto que no es así. Si se recuerda, en el ámbito de la educación moral se da una constante reflexión crítica en virtud de un corpus de conocimiento, el cual sirve como base teórica para orientar las acciones y por tanto articular los valores y principios. Se trata de llevar a cabo una hermenéutica que sea crítica, para no conformarse con las interpretaciones que tradicionalmente hayan sido asumidas o que hayan sido mayoritarias. El profesor Emilio Martínez Navarro aclara muy bien esta cuestión:

En términos de la ética discusiva, que es una de las más relevantes éticas contemporáneas, cualquier actividad que se pretenda legítima ha de reconocer que los afectados por las normas de dicha actividad son personas, son interlocutores válidos, y esto exige considerar que tales normas únicamente serán justas si pueden ser aceptadas por todos ellos tras un diálogo celebrado en condiciones de racionalidad (Martínez, 2010, p. 90).

La ética discursiva propuesta por Apel tiene como uno de sus objetivos fundamentar en la práctica normas morales que se han construido a partir de un proceso argumentativo y participativo. En este caso, un proceso que se considera que se puede desarrollar en el ámbito educativo para así allanar el propósito desde un plano pedagógico. El ejercicio argumentativo, propio de la ética discursiva, se desarrolla a partir del intercambio de razones que encuentran su origen en la vida cotidiana, es decir, en el mundo de la vida. Tiene pretensiones de universalización y de responsabilidad, pues se entiende que nos encontramos en un mundo globalizado con problemas de carácter global. Adela Cortina trata el carácter de universalización presente en el discurso práctico expresándonos lo siguiente:

[...] el principio de universalización va a funcionar como regla de argumentación para efectuar el tránsito desde las consecuencias a las normas 
legítimas. Y en este sentido, se acepta sin ambages la intuición kantiana de utilizar la universalización como procedimiento formal para la comprobación de normas; nunca como un principio moral con contenido o como un principio ético. La formulación de la universalidad es un test para comprobar la legitimidad de las máximas, y no un mandato que se debe cumplir (Cortina, 2008, p.153).

El ejercicio argumentativo de la ética discursiva orienta acciones y conductas de cooperación a través del diálogo intersubjetivo, pues es solo a través de la intersubjetividad como se podrán llevar a cabo las actuaciones cooperadas que plantea el programa de Filosofía para Niños. Este ejercicio que se promueve, radica en la corresponsabilidad que se ciñe a la permanente crítica y corrección de nuestras acciones. La argumentación se convierte en una práctica inevitable en este modo de funcionar, es decir es imprescindible y debe de estar presente en todo comportamiento que quiera caracterizarse como racional. Se da una superación del relativismo moral y del escepticismo ético que caracterizan la desigualdad presente en el mundo de la vida. La ética de la co-responsabilidad se hace necesaria en el ámbito educativo pues es un espacio idóneo desde el que hay que plantear soluciones para un mundo carente de ellas. De esta manera Apel considera lo siguiente:

[...] pues de lo que se trata, por vez primera en la historia del hombre, es de asumir la responsabilidad solidaria por las consecuencias y subconsecuencias a escala mundial de las actividades colectivas de los hombres -como, por ejemplo, la aplicación industrial de la ciencia y de la técnica- y de organizar esa responsabilidad como praxis colectiva (Apel, 1997, p. 148).

La educación basada en la ética de la responsabilidad dota de sentido nuestra mirada sobre el mundo pues se comprende que la situación actual no se da per se como consecuencia del devenir histórico, sino que encuentra su origen en actitudes propias de la racionalidad instrumental y también de la irracionalidad.

El concepto de responsabilidad aporta a la ética discursiva de Apel un carácter dialéctico y ahora veremos por qué. Esta aportación de carácter dialéctico, establece una conexión entre los aspectos trascendentales, propios de la teoría, y los aspectos procedimentales propios de la praxis. Tal conexión dialéctica permite acercar la propuesta ética formalista, procedimentalista y universalista a la realidad cotidiana y concreta, en este caso la clase como comunidad de investigación, para llevar a cabo una actuación política y democrática. Si es observada detenidamente, se podrá observar, 
que Apel relaciona una comunidad real de comunicación con una comunidad ideal de comunicación. Ya nos señala esto mismo la filósofa Cortina:

La pragmática trascendental de Apel, como ya apuntamos, se caracteriza por guardar una peculiar relación con la experiencia. Admite, sin problemas, que el trascendentalismo no rehúsa tratar con los hechos contingentes, sino que los necesita para su propia vida, y no sólo en el contexto de descubrimiento (Cortina, 1988, p. 135).

Una vez visto esto, es importante señalar que la responsabilidad moral implícita en la ética discursiva de Apel, encuentra su origen en la actividad del aprendizaje. Existe una importante conexión entre el aprendizaje y la actitud responsable, que hace necesario construir procesos de participación en el ámbito educativo que caminen hacia el establecimiento del êthos de responsabilidad. Hay pues una relación innegable entre responsabilidad y pedagogía.

La responsabilidad moral se desarrolla en el terreno de tres actividades prácticas muy importantes de abordar. Una de ellas tiene que ver con las normas y su fundamentación a partir de la argumentación, algo que ya se ha visto en páginas anteriores. Otra tiene que ver con la orientación de las acciones, siempre sometidas a la permanente reflexión crítica con carácter correctivo. Pero también se desarrolla la responsabilidad en la constante búsqueda de la correcta conexión entre fundamentación y acción, es decir, entre lo que se construye a partir del diálogo argumentativo y lo que luego, finalmente, se realiza.

\section{Conclusiones}

La educación en valores para la construcción de una ética cívica es una expresión que emerge con el deseo de introducir la ética en el ámbito político con el fin de construir sentidos comunes y proyectos colectivos.

En este sentido, se ha entendido lo político en sentido amplio, afirmando que es necesario un proceso de politización de la educación para profundizar la democracia en el horizonte de la alteridad. La educación cívica debe ser necesariamente política porque está ligada a un proyecto de transformación social.

Así pues, la educación ciudadana a través del método dialógico no debe de convertirse únicamente en una asignatura, algo que hay que reconocer que es muy importante, sino que implica una praxis comprometida desde la que interpretar e intervenir la realidad. La educación cívica despliega una pedagogía de lo público. Su objetivo es desarrollar capaci- 
dades para hacer sujetos sociales y políticos como agentes de cambio y relaciones democráticas. Por ello, las prácticas participativas son educativas en sí mismas, en el ejercicio participativo los actores involucrados, tanto ciudadanos, como poderes públicos, adquieren e intercambian aprendizajes que legitiman la acción política.

El diálogo es el marco en el que se desarrolla la acción participativa. El diálogo es intersubjetivo porque es incluyente, integra todas las cosmovisiones involucradas en el escenario concreto. La premisa que sustenta el diálogo es el respeto emanado del vínculo social que va más allá de la tolerancia, es el respeto que valora lo otro diferente como potencial de creatividad y de transformación.

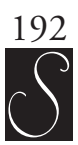

\section{Bibliografía}

ADORNO, Theodor

1998 Educación para la emancipación: conferencias y conversaciones con Hellmut Becker (1959-1969). Madrid: Morata.

APEL, Karl-Otto

1995 La transformación de la filosofía. Madrid: Taurus.

1986 Estudios éticos. Barcelona: Alfa.

1997 Teoría de la verdad y ética del discurso. Barcelona: Paidós.

BENJAMIN, Walter

1974 Reflexiones sobre niños, juguetes, libros infantiles, jóvenes y educación. Buenos Aires: Nueva visión.

CORTINA, Adela

1988 Razón comunicativa y responsabilidad solidaria. Salamanca: Sígueme.

2008 La escuela de Fráncfort: crítica y utopía. Madrid: Síntesis.

2010 Ética mínima. Madrid: Tecnos.

HABERMAS, Jürgen

1996 Textos y contextos. Barcelona: Ariel.

LIPMAN, Matthew

2001 Pensamiento complejo y educación. Madrid: Ediciones de la Torre. Martínez, Emilio

2010 Ética profesional de los profesores. Bilbao: Desclée de Brouwer.

Fecha de recepción del documento: 1 de agosto de 2016 Fecha de revisión del documento: 15 de septiembre de 2016 Fecha de aceptación del documento: 20 de noviembre de 2016 Fecha de publicación del documento: Enero de 2017 